\title{
Nanoscale
}

Check for updates

Cite this: Nanoscale, 2019, 11, 11736

\section{Hierarchically heterostructured metal hydr(oxy)oxides for efficient overall water splitting $\dagger$}

\author{
Yang Liu, $t^{a}, \mathrm{~b}$ Fengmei Wang, $\stackrel{+}{a}^{a}$ Tofik Ahmed Shifa, ${ }^{a}$ Jie Li, ${ }^{a, b}$ Jing Tai, ${ }^{c}$ Yu Zhang, ${ }^{a}$ \\ Junwei Chu, ${ }^{a}$ Xueying Zhan, ${ }^{a}$ Chongxin Shan*d and Jun $\mathrm{He}$ (D) *a,b
}

Received 8th April 2019

Accepted 22nd May 2019

DOI: $10.1039 / c 9 n r 02988$ e

rsc.li/nanoscale

\begin{abstract}
The design of highly efficient electrocatalysts containing non-precious metals is crucial for promoting overall water splitting in alkaline media. In particular, Janus catalysts simultaneously facilitating the hydrogen evolution reaction (HER) and oxygen evolution reaction (OER) are desirable. Herein, we fabricated a unique hierarchical heterostructure via growing $\mathrm{Ni}_{4} \mathrm{~W}_{6} \mathrm{O}_{21}(\mathrm{OH})_{2} \cdot 4 \mathrm{H}_{2} \mathrm{O}$ (denoted as $\mathrm{Ni}-\mathrm{W}-\mathrm{O}$ ) nanosheets on $\mathrm{NiMoO}_{4}$ rods, which was indispensable for regulating the morphology of the $\mathrm{Ni}-\mathrm{W}-\mathrm{O}$ structure. This heterostructure of $\mathrm{Ni}-\mathrm{W}-\mathrm{O} / \mathrm{NiMOO}_{4}$ could be utilized as an electrocatalyst to realize superior activity for overall water splitting in $1.0 \mathrm{M} \mathrm{KOH}$. It substantially promoted overall water splitting with $1.6 \mathrm{~V}$ at $30 \mathrm{~mA} \mathrm{~cm}{ }^{-2}$, outperforming numerous bifunctional electrocatalysts under the same conditions. Notably, the remarkable stability for continuously splitting water endowed this hierarchical heterostructure with potential applications on a large scale. This work emphasizes the effectively controlled growth of heterostructured non-noble-metal catalysts for energy-conversion reaction.
\end{abstract}

\section{Introduction}

Electrochemical water splitting, involving the hydrogen reaction (HER) and oxygen evolution reaction (OER), is one of the most promising technologies to alleviate the environmental crisis. $^{1,2}$ Platinum (Pt)- and iridium (Ir)- or ruthenium (Ru)based oxides are acknowledged as superior catalysts for HER and OER, respectively. ${ }^{3,4}$ However, their scarcity and high cost hinder their industrial applications to practically solve the current global energy problem. In water splitting reactions, OER is kinetically sluggish and thermodynamically challenging as compared to HER. Remarkable development ${ }^{5-7}$ has been made so far in regard to promising catalysts for HER in acidic electrolytes. It is also true that OER occurs more easily in an alkaline electrolyte than in an

\footnotetext{
${ }^{a}$ CAS Center for Excellence in Nanoscience, CAS Key Laboratory of Nanosystem and Hierarchical Fabrication, National Center for Nanoscience and Technology, Beijing 100190, China. E-mail: hej@nanoctr.cn

${ }^{b}$ Center of Materials Science and Optoelectronics Engineering, University of Chinese Academy of Sciences, Beijing 100049, P. R. China

${ }^{c}$ Testing and Analysis Center, Institute of Chemistry, Chinese Academy of Sciences, Beijing 100190, China

${ }^{d}$ School of Physics and Engineering, Zhengzhou University, Zhengzhou 450001, China.E-mail: cxshan@zzu.edu.cn

$\dagger$ Electronic supplementary information (ESI) available. See DOI: 10.1039/ c9nr02988e

\$These authors contributed equally.
}

acidic electrolyte. ${ }^{8,9}$ Therefore, efforts are being devoted to the rational design of novel electrocatalysts that simultaneously catalyze both HER and OER under the same conditions. For instance, FeCoNi ternary alloys encapsulated in graphene layers can tune the electronic structures of materials to exhibit superior catalytic performances. ${ }^{10}$ Also, $\mathrm{Cu}$ nanowires grown on few-layer NiFe layered double hydroxide $(\mathrm{LDH})$ nanosheets provide high surface areas, fast electron transport, and open channels for effective gas release, effectively improving the overall water splitting performance. ${ }^{11}$ Notably, metal (hydr)oxides containing Ni atoms, e.g., Ni-Mo oxides, ${ }^{12-15} \mathrm{Ni}$-Co oxides, ${ }^{16,17}$ and $\mathrm{Ni}-\mathrm{Fe}$ layered double hydroxides ${ }^{18}$ have been intensively explored to generate oxygen gas in alkaline media. The adsorption energy of hydroxyl ions on Ni-based hydr(oxy)oxide can be easily tuned by introducing other metal atoms. ${ }^{19,20}$ Meanwhile, nickel (Ni) atoms can act as water dissociation centers when combined with other transition metal atoms, especially Mo atoms. ${ }^{21,22}$ This suggests that binary Ni- and Mo-based oxides are prospective candidates for splitting water. However, there are only a few studies about the OER catalytic activity of Ni-Mo oxides.

Here, we fabricated a hierarchical heterostructure of $\mathrm{Ni}_{4} \mathrm{~W}_{6} \mathrm{O}_{21}(\mathrm{OH})_{2} \cdot 4 \mathrm{H}_{2} \mathrm{O}$ nanosheets grown on $\mathrm{NiMoO}_{4}$ rods (denoted as $\mathrm{Ni}-\mathrm{W}-\mathrm{O} / \mathrm{NiMoO}_{4}$ ). There were some remarkable advantages of fabricating this type of hierarchical heterostructure. First, the $\mathrm{NiMoO}_{4}$ micro-structure not only provided 
a high surface area but also boosted the HER and OER activities by increasing the release of $\mathrm{H}_{2}$ and $\mathrm{O}_{2}$ bubbles from the surface of the electrode. ${ }^{23}$ Second, the two types of Ni-based materials $\mathrm{Ni}-\mathrm{W}-\mathrm{O}$ and $\mathrm{NiMoO}_{4}$ could effectively promote water dissociation on their surface due to the existence of $\mathrm{Ni}$ atoms. Furthermore, the effective interaction between $\mathrm{Ni}-\mathrm{W}-\mathrm{O}$ and $\mathrm{NiMoO}_{4}$ could regulate the electronic structure of the electrocatalyst for synergistically improving the HER and OER activities. The hierarchical $\mathrm{Ni}-\mathrm{W}-\mathrm{O} / \mathrm{NiMoO}_{4}$ on a conductive Ni foam was synthesized via a two-step hydrothermal method. In particular, the $\mathrm{NiMoO}_{4}$ rod played a crucial role in the realization of $\mathrm{Ni}-\mathrm{W}-\mathrm{O}$ nanosheets. The electronic coupling on the interface between $\mathrm{Ni}-\mathrm{W}-\mathrm{O}$ and $\mathrm{NiMoO}_{4}$ endowed our novel material with bifunctional electrocatalytic activity in 1.0 $\mathrm{M} \mathrm{KOH}$. In HER, the synthesized hierarchical Ni-W-O/NiMoO electrode showed a low overpotential of $\sim 52 \mathrm{mV}$, which was close to the value obtained using a Pt foil under the same conditions at a current density of $10 \mathrm{~mA} \mathrm{~cm}{ }^{-2}$. The Tafel slope of $80 \mathrm{mV} \mathrm{dec}{ }^{-1}$, which was much lower than those of $\mathrm{NiMoO}_{4}$ (95 $\mathrm{mV} \mathrm{dec}^{-1}$ ) and pure $\mathrm{Ni}-\mathrm{W}-\mathrm{O}\left(131 \mathrm{mV} \mathrm{dec}^{-1}\right)$, was also recorded for the $\mathrm{Ni}-\mathrm{W}-\mathrm{O} / \mathrm{NiMoO}_{4}$ electrode. Moreover, this heterostructure exhibited a superior OER performance with an overpotential of $253 \mathrm{mV}$ at $30 \mathrm{~mA} \mathrm{~cm} \mathrm{~cm}^{-2}$ and a Tafel slope of $92 \mathrm{mV} \mathrm{dec}^{-1}$. The observed superior stability, withstanding continuous measurements in $1.0 \mathrm{M} \mathrm{KOH}$ for more than 3 days, further demonstrated its potential for industrial utilization. As expected, overall water splitting based on the $\mathrm{Ni}-\mathrm{W}-\mathrm{O} / \mathrm{NiMoO}_{4}$ heterostructure was realized under a low voltage of $1.6 \mathrm{~V}$ at a current density of $30 \mathrm{~mA} \mathrm{~cm} \mathrm{~cm}^{-2}$. Our results offer a paradigm for establishing a platform for synergistic catalysis.

\section{Results and discussion}

Hierarchical $\mathrm{Ni}-\mathrm{W}-\mathrm{O} / \mathrm{NiMoO}_{4}$ heterostructures were prepared on a porous Ni foam (NF, Fig. S1a $\dagger$ ) through a simple two-step hydrothermal method, and they exhibited sufficient mechanical strength and conductivity, as illustrated in Fig. 1a. This yielded hierarchically assembled $\mathrm{Ni}-\mathrm{W}-\mathrm{O}$ nanosheets onto the $\mathrm{NiMoO}_{4}$ rods (denoted as $\mathrm{Ni}-\mathrm{W}-\mathrm{O} / \mathrm{NiMoO}_{4}$ ). The concentrations of the precursors such as $\mathrm{NiCl}_{2} \cdot 6 \mathrm{H}_{2} \mathrm{O}$ and $\left(\mathrm{NH}_{4}\right)_{10} \mathrm{~W}_{12} \mathrm{O}_{41} \cdot x \mathrm{H}_{2} \mathrm{O}$ played a significant role in tuning the morphology of the as-grown material on the $\mathrm{NiMoO}_{4}$ rods. Hence, we made careful optimization to obtain nanosheet morphology for superior electrocatalysis. To this end, the desired morphology of the Ni-W-O nanostructure on $\mathrm{NiMoO}_{4}$ rods was obtained with the concentrations of $0.033 \mathrm{~mol} \mathrm{~L}^{-1}$ for $\mathrm{NiCl}_{2} \cdot 6 \mathrm{H}_{2} \mathrm{O}$ and $0.033 \mathrm{~mol} \mathrm{~L} \mathrm{~L}^{-1}$ for $\left(\mathrm{NH}_{4}\right)_{10} \mathrm{~W}_{12} \mathrm{O}_{41} \cdot x \mathrm{H}_{2} \mathrm{O}$. Accordingly, the as-prepared heterostructure is defined as "Ni-W-O/NiMoO 4 -1". For comparison, a heterostructure (Ni$\left.\mathrm{W}-\mathrm{O} / \mathrm{NiMoO}_{4}-2\right)$ with increased concentrations of $\mathrm{NiCl}_{2} \cdot 6 \mathrm{H}_{2} \mathrm{O}$ $\left(0.066 \mathrm{~mol} \mathrm{~L}^{-1}\right)$ and $\left(\mathrm{NH}_{4}\right)_{10} \mathrm{~W}_{12} \mathrm{O}_{41} \cdot x \mathrm{H}_{2} \mathrm{O}\left(0.066 \mathrm{~mol} \mathrm{~L}^{-1}\right)$ was also prepared. From the scanning electron microscopy (SEM) image in Fig. $\mathrm{S} 1 \mathrm{~b}, \dagger$ it can be seen that the diameter and length of each $\mathrm{NiMoO}_{4}$ rod are around 400-500 nm and 20-30 $\mu \mathrm{m}$, respectively, and it is capable of hosting the incoming nanosheet. The energy dispersive X-ray spectrum (EDX, Fig. S1 $\mathrm{C}^{\dagger}$ ) reveals the existence of Mo, Ni and $\mathrm{O}$ elements in the formed $\mathrm{NiMoO}_{4}$. Meanwhile, the X-ray diffraction pattern (XRD, Fig. $\mathrm{S} 2 \dagger$ ) of the as-synthesized $\mathrm{NiMoO}_{4}$ crystals demonstrates the typical diffraction peaks located at $14.3^{\circ}, 28.9^{\circ}$ and $32.6^{\circ}$, which are well identified as the (110), (220) and (022)

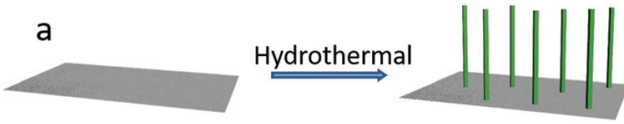

NF
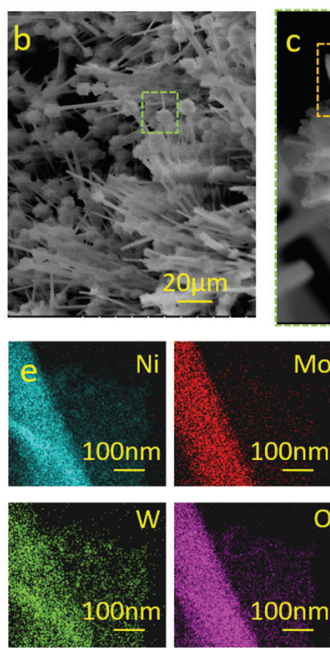

Hydrothermal

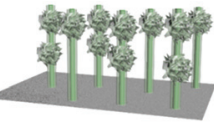

$\mathrm{Ni}-\mathrm{W}-\mathrm{O} / \mathrm{NiMoO}_{4} / \mathrm{NF}$
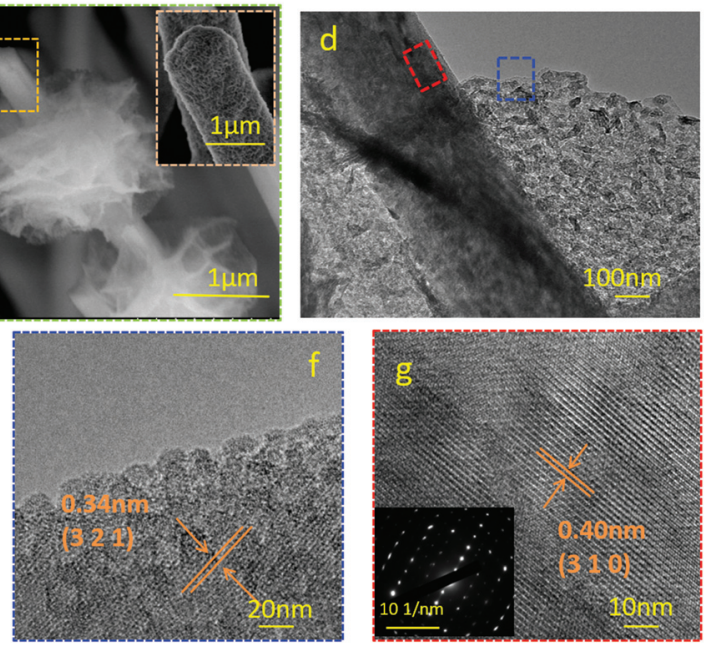

Fig. 1 (a) Schematic diagram of the synthesis of the $\mathrm{Ni}-\mathrm{W}-\mathrm{O} / \mathrm{NiMoO}_{4}-1$ heterostructure. (b-c) SEM images of $\mathrm{Ni}-\mathrm{W}-\mathrm{O} / \mathrm{NiMoO}{ }_{4}-1$ heterostructure under different magnifications. The inset in c: the part marked with orange line. TEM image (d), EDX mapping (e), and HRTEM images ( $f-g)$ of the heterostructure. Inset in g: the SAED patterns marked in d. 
planes of the monoclinic $\mathrm{NiMoO}_{4}$ phase, respectively (PDF\#330948). The other diffraction peaks at $44.5^{\circ}, 51.9^{\circ}$ and $76.1^{\circ}$ are assigned to the $\mathrm{Ni}$ foam. The SEM images of the $\mathrm{Ni}-\mathrm{W}-\mathrm{O} /$ $\mathrm{NiMoO}_{4}-1$ arrays under different magnifications are shown in Fig. $1 \mathrm{~b}$ and $\mathrm{c}$. The size of the obtained microstructures along with the nanosheets was about $2 \mu \mathrm{m}$ and the diameter of the rods further increased to $1 \mu \mathrm{m}$ (the inset of Fig. 1c). As shown in Fig. 1d, the transmission electron microscopy (TEM) image of $\mathrm{Ni}-\mathrm{W}-\mathrm{O} / \mathrm{NiMoO}_{4}-1$ further displays that the $\mathrm{Ni}-\mathrm{W}-\mathrm{O}$ nanosheets uniformly cover the surface of the $\mathrm{NiMoO}_{4}$ rods. This corroborates the achievement of a unique hierarchical heterostructure. Also, the EDX mapping of an Ni-W-O/ $\mathrm{NiMoO}_{4}-1$ microrod (Fig. 1e) exhibits the uniform distribution of the $\mathrm{Ni}, \mathrm{Mo}, \mathrm{W}$ and $\mathrm{O}$ elements throughout the microrod. The lattice fringes with interplanar distances of 0.34 and $0.4 \mathrm{~nm}$ in the high-resolution TEM images (HRTEM, Fig. if and $\mathrm{g}$ ) of the nanosheet can be indexed to the (321) and (310) planes of the $\mathrm{Ni}_{4} \mathrm{~W}_{6} \mathrm{O}_{21}(\mathrm{OH})_{2} \cdot 4 \mathrm{H}_{2} \mathrm{O}$ crystal (PDF\#47-0143), respectively. Moreover, the selected area electron diffraction (SAED, inset of Fig. 1g) pattern also demonstrates its high crystallinity. As the concentration of $\mathrm{NiCl}_{2} \cdot 6 \mathrm{H}_{2} \mathrm{O}$ and $\left(\mathrm{NH}_{4}\right)_{10} \mathrm{~W}_{12} \mathrm{O}_{41} \cdot x \mathrm{H}_{2} \mathrm{O}$ doubled $\left(0.066 \mathrm{~mol} \mathrm{~L}^{-1}\right)$, the morphology of $\mathrm{Ni}-\mathrm{W}-\mathrm{O} / \mathrm{NiMoO}_{4}-2$ changed accordingly. Its SEM image (Fig. S3†) shows that microcubes instead of sheets with a size of around $4-5 \mu \mathrm{m}$ assemble at the rods. Meanwhile, from the XRD pattern, XPS spectra and TEM images of Ni-W-O/ $\mathrm{NiMoO}_{4}$-2 in Fig. S4-6, $\dagger$ we can see that there is no obvious difference in the crystal phase and the components. For revealing the growth mechanism in this process, an intermediate sample $\left(\mathrm{Ni}-\mathrm{W}-\mathrm{O} / \mathrm{NiMoO}_{4}-1.5\right)$ was also synthesized using a moderate concentration $\left(0.05 \mathrm{~mol} \mathrm{~L}{ }^{-1}\right)$ of $\mathrm{NiCl}_{2} \cdot 6 \mathrm{H}_{2} \mathrm{O}$ and $\left(\mathrm{NH}_{4}\right)_{10} \mathrm{~W}_{12} \mathrm{O}_{41} \cdot x \mathrm{H}_{2} \mathrm{O}$. From the SEM image in Fig. $\mathrm{S} 7, \dagger$ we infer that the sheets on the $\mathrm{NiMoO}_{4}$ rods consist of particles and demonstrate high thickness. This result indicates that the concentration of the precursor plays a key role in controlling the morphology of the heterostructure. A low concentration is beneficial for the growth of thin $\mathrm{Ni}-\mathrm{W}-\mathrm{O}$ nanosheets due to the slow reaction rate. We also tried the experiment without the $\mathrm{NiMoO}_{4}$ rods to practically determine the role of the first growth step in tuning the morphology of the hierarchical heterostructure. Fig. S8 $\uparrow$ shows that the obtained $\mathrm{Ni}-\mathrm{W}-\mathrm{O}$ structure grown directly on a $\mathrm{Ni}$ foam appears as microcubes; this is significantly different from the case where there is $\mathrm{NiMoO}_{4}$ prior to the growth of Ni-W-O nanosheets. This result reveals that the $\mathrm{NiMoO}_{4}$ rods are essential for directing the growth of Ni-W-O into nanosheet morphology.

In order to further characterize the components of the $\mathrm{Ni}-$ $\mathrm{W}-\mathrm{O} / \mathrm{NiMoO}_{4}-1$ heterostructure, the XRD pattern was obtained (Fig. 2a). Compared with the XRD pattern of pure $\mathrm{NiMoO}_{4}$ rods on a $\mathrm{Ni}$ foam, new diffraction peaks at $9.7^{\circ}, 16.9^{\circ}, 31.2^{\circ}$, etc. emerged for the $\mathrm{Ni}-\mathrm{W}-\mathrm{O} / \mathrm{NiMoO}_{4}-1$ arrays, demonstrating the existence of the cubic $\mathrm{Ni}_{4} \mathrm{~W}_{6} \mathrm{O}_{21}(\mathrm{OH})_{2} \cdot 4 \mathrm{H}_{2} \mathrm{O}$ phase (PDF\#470143). Moreover, the X-ray photoelectron spectra (XPS, Fig. 2b and Fig. S9 $\dagger$ ) of various samples were recorded for studying the electronic structure of the heterostructure. The $\mathrm{Ni} 2 \mathrm{p}_{3 / 2}$ and $2 \mathrm{p}_{1 / 2}$ peaks of $\mathrm{NiMoO}_{4}$ (Fig. 2c) are located at 856.60 and $874.37 \mathrm{eV}$, respectively, along with two satellite peaks at 862.40 and $880.19 \mathrm{eV}^{24,25}$ It should be noted that there was a shift of $0.6 \mathrm{eV}$ to lower binding energies $(856.0 \mathrm{eV}$ and $873.8 \mathrm{eV}$ for $\mathrm{Ni}$ $2 \mathrm{p}_{3 / 2}$ and $2 \mathrm{p}_{1 / 2}$, respectively) for $\mathrm{Ni}-\mathrm{W}-\mathrm{O} / \mathrm{NiMoO}_{4}-1$ compared to that for pure $\mathrm{NiMoO}_{4}$. This revealed the regulation of the electronic structure after the construction of the $\mathrm{Ni}-\mathrm{W}-\mathrm{O} /$ $\mathrm{NiMoO}_{4}$ heterostructure. Fig. $2 \mathrm{~d}$ demonstrates the deconvolution analysis of the Mo $3 \mathrm{~d}$ bonding modes in various samples. For the $\mathrm{NiMoO}_{4}$ rods, the peaks at binding energies of 232.20 $\mathrm{eV}$ and $235.25 \mathrm{eV}$ corresponding to $\mathrm{Mo} 3 \mathrm{~d}_{5 / 2}$ and Mo $3 \mathrm{~d}_{3 / 2}$ are in agreement with the previously reported values for the $\mathrm{Mo}^{6+}$ oxidation state. ${ }^{24}$ After growing $\mathrm{Ni}-\mathrm{W}-\mathrm{O}$ nanosheets, the
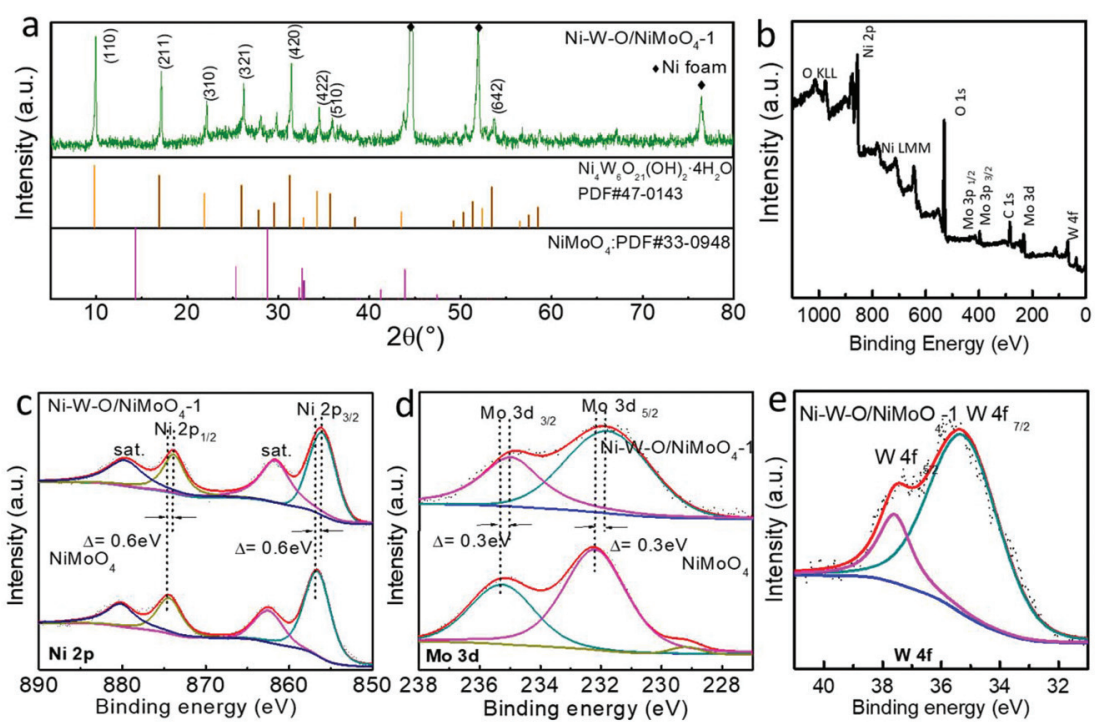

Fig. 2 (a) XRD pattern, XPS analysis of survey scan (b), Ni $2 p$ (c), Mo 3d (d) and W $2 f$ (e) spectra for the obtained Ni-W-O/NiMoO $4-1$ heterostructure. 
Mo $3 \mathrm{~d}_{5 / 2}$ peak shifted by $0.3 \mathrm{eV}$ to a lower binding energy, verifying that charge redistribution occurred on the interface. The two peaks situated at 35.23 and $37.6 \mathrm{eV}$ in the $\mathrm{W} 4 \mathrm{f}$ region are assigned to $\mathrm{W} 4 \mathrm{f}_{7 / 2}$ and $\mathrm{W} 4 \mathrm{f}_{5 / 2}$ of $\mathrm{W}^{6+}$, respectively (Fig. $2 \mathrm{e}$ ). ${ }^{26}$ This result suggests that the $\mathrm{W}$ element in the heterostructure can possibly act as electron-donating sites to tune the electronic structure of $\mathrm{NiMoO}_{4}$.

The electrocatalytic activities of various samples were evaluated in $1.0 \mathrm{M} \mathrm{KOH}$. A typical three-electrode setup with an $\mathrm{Hg} / \mathrm{HgO}$ electrode and a glass carbon plate as the reference and counter electrodes, respectively, was utilized here. Ni-W$\mathrm{O} / \mathrm{NiMoO}_{4}-1$ acted as the working electrode. For comparison, the pure $\mathrm{NiMoO}_{4}, \mathrm{Ni}-\mathrm{W}-\mathrm{O}$, and $\mathrm{Ni}-\mathrm{W}-\mathrm{O} / \mathrm{NiMoO}_{4}-2$ electrodes were also measured under the same conditions. Their HER activities were investigated in $\mathrm{N}_{2}$ gas (99.99\%)-saturated $1.0 \mathrm{M}$ $\mathrm{KOH}$. The polarization curves shown in Fig. 3a display the superior HER performance of the $\mathrm{Ni}-\mathrm{W}-\mathrm{O} / \mathrm{NiMoO}_{4}-1$ electrode with an overpotential $\left(\eta_{10}\right)$ of $\sim 52 \mathrm{mV}$, which is much smaller than those of the Ni-W-O/NiMoO${ }_{4}^{-2}(\sim 100 \mathrm{mV})$, $\mathrm{NiMoO}_{4}(\sim 234 \mathrm{mV})$, and $\mathrm{Ni}-\mathrm{W}-\mathrm{O}(258 \mathrm{mV})$ electrodes at $10 \mathrm{~mA} \mathrm{~cm} \mathrm{~cm}^{-2}$. Importantly, the catalytic activity of $\mathrm{Ni}-\mathrm{W}-\mathrm{O} /$ $\mathrm{NiMoO}_{4}-1$ was comparable to that of a pure Pt foil $(30 \mathrm{mV}$ at $10 \mathrm{~mA} \mathrm{~cm}^{-2}$ ). Thus, the growth of the $\mathrm{Ni}-\mathrm{W}-\mathrm{O}$ nanosheets on the surface of $\mathrm{NiMoO}_{4}$ endowed a highly enhanced performance for the heterostructure due to its optimum morphology and synergistic effect. The $\eta_{10}$ values of various electrodes shown in Fig. 3b obviously demonstrate the outstanding performance of the $\mathrm{Ni}-\mathrm{W}-\mathrm{O} / \mathrm{NiMoO}_{4}-1$ heterostructure (Table S1†). The corresponding Tafel plots are shown in Fig. 3c. As expected, the Tafel slope of $\mathrm{Ni}-\mathrm{W}-\mathrm{O} / \mathrm{NiMoO}_{4}-1$ is
$80 \mathrm{mV} \mathrm{dec}{ }^{-1}$, which is much lower than those of the $\mathrm{Ni}-\mathrm{W}-\mathrm{O} /$ $\mathrm{NiMoO}_{4}-2\left(158 \mathrm{mV} \mathrm{dec}{ }^{-1}\right), \mathrm{NiMoO}_{4}\left(95 \mathrm{mV} \mathrm{dec}{ }^{-1}\right)$ and pure $\mathrm{Ni}-\mathrm{W}-\mathrm{O}\left(131 \mathrm{mV} \mathrm{dec}^{-1}\right)$ electrodes. The higher Tafel slopes of the $\mathrm{Ni}-\mathrm{W}-\mathrm{O} / \mathrm{NiMoO}_{4}-2$ and $\mathrm{Ni}-\mathrm{W}-\mathrm{O}$ electrodes indicated that the microcube morphology of $\mathrm{Ni}-\mathrm{W}-\mathrm{O}$ hindered the adsorption of $\mathrm{H}_{2} \mathrm{O}$ molecules $\left(\mathrm{H}_{2} \mathrm{O}+\mathrm{M}+\mathrm{e}^{-} \rightarrow \mathrm{M}^{-} \mathrm{H}^{*}+\mathrm{OH}^{-}\right.$, where $\mathrm{M}$ denotes the electrocatalyst) on the surface. As an important descriptor to evaluate the kinetics of electrocatalysts, we measured the exchange current density $\left(j_{0}\right)$ and found a value of $4.615 \mathrm{~mA} \mathrm{~cm}^{-2}$ for the $\mathrm{Ni}-\mathrm{W}-\mathrm{O} / \mathrm{NiMoO}_{4}-1$ electrode, which outperformed the $\mathrm{Ni}-\mathrm{W}-\mathrm{O} / \mathrm{NiMoO}_{4}-2 \quad\left(2.710 \mathrm{~mA} \mathrm{~cm}^{-2}\right)$, $\mathrm{NiMoO}_{4}\left(0.034 \mathrm{~mA} \mathrm{~cm}{ }^{-2}\right)$, and pure Ni-W-O $\left(0.101 \mathrm{~mA} \mathrm{~cm}^{-2}\right)$ electrodes and the Pt foil $\left(1.2 \mathrm{~mA} \mathrm{~cm}^{-2}\right)$. Additionally, electrochemical impedance spectroscopy (EIS) was used to examine the electron transfer process during hydrogen generation (Fig. S10†). The equivalent circuit consisting of a constant phase element, series resistance $\left(R_{\mathrm{S}}\right)$ and charge transfer resistance $\left(R_{\mathrm{ct}}\right)$ is provided in the inset of Fig. S10. $\dagger$ Notably, the smallest values of $R_{\mathrm{S}}(0.8 \Omega)$ and $R_{\mathrm{ct}}(2 \Omega)$ recorded for the Ni$\mathrm{W}-\mathrm{O} / \mathrm{NiMoO}_{4}-1$ electrode substantiated the ease of electron transfer and hence the enhanced kinetics of catalysis across the entire hierarchical heterostructure as compared to those of the other samples. We then evaluated the electrochemical stability of the $\mathrm{Ni}-\mathrm{W}-\mathrm{O} / \mathrm{NiMoO}_{4}$ heterostructure to assess the robustness of the electrode. To do this, the electrode was subjected to an accelerated degradation test of 5000 continuous cyclic voltammetry (CV) cycles, and the linear sweep voltammetry (LSV) curves were compared before and after the test. It can be seen (Fig. 3d) that there is only an $8 \%$ increment in the potential at a current density of $10 \mathrm{~mA} \mathrm{~cm} \mathrm{~cm}^{-2}$. Moreover, a neg-
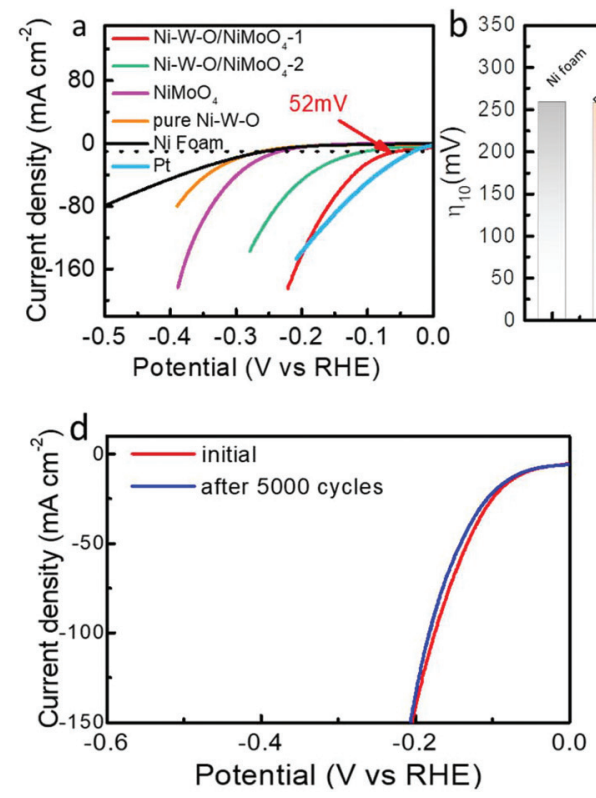
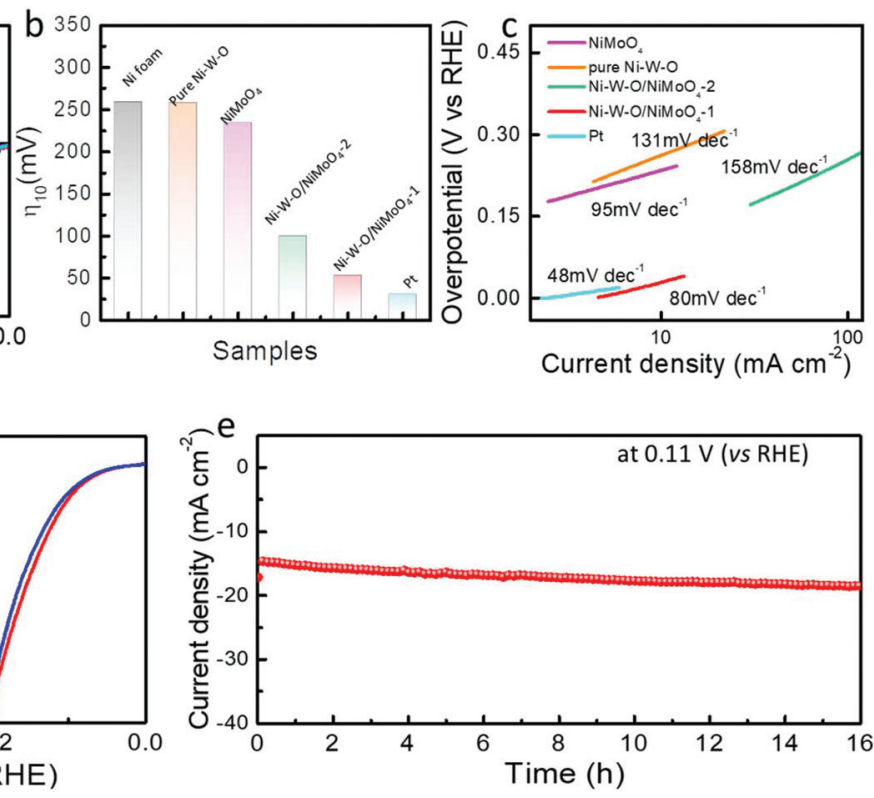

Fig. 3 Electrochemical activity for HER in $1.0 \mathrm{M} \mathrm{KOH:} \mathrm{(a)} \mathrm{HER} \mathrm{polarization} \mathrm{curve} \mathrm{at} \mathrm{a} \mathrm{scan} \mathrm{rate} \mathrm{of} 5 \mathrm{mV} \mathrm{s}^{-1}$ for various electrodes. (b) Comparison of the corresponding $\eta_{10}$ values collected based on the polarization curves in (a) for various electrodes. (c) Tafel plots obtained from the corresponding polarization curves in (a). (d) Comparison of polarization curves before and after $5000 \mathrm{CV}$ cycles. (e) Chronoamperometry testing of the Ni-W-O/ $\mathrm{NiMoO}_{4}-1$ electrode at $0.11 \mathrm{~V}$ (vs. RHE). 

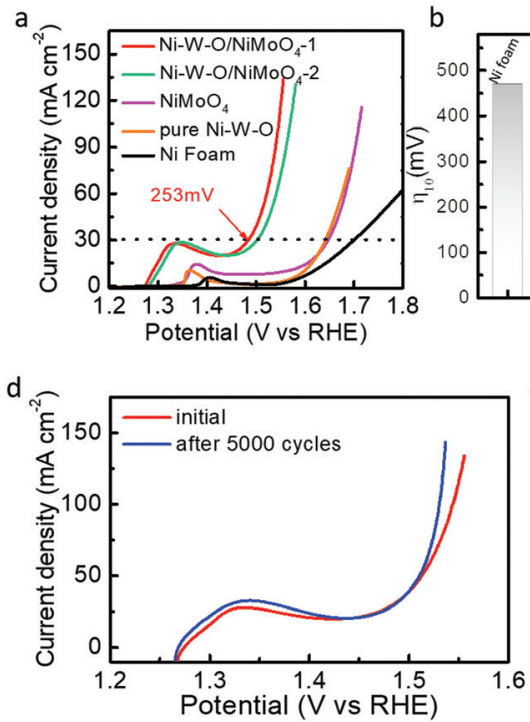
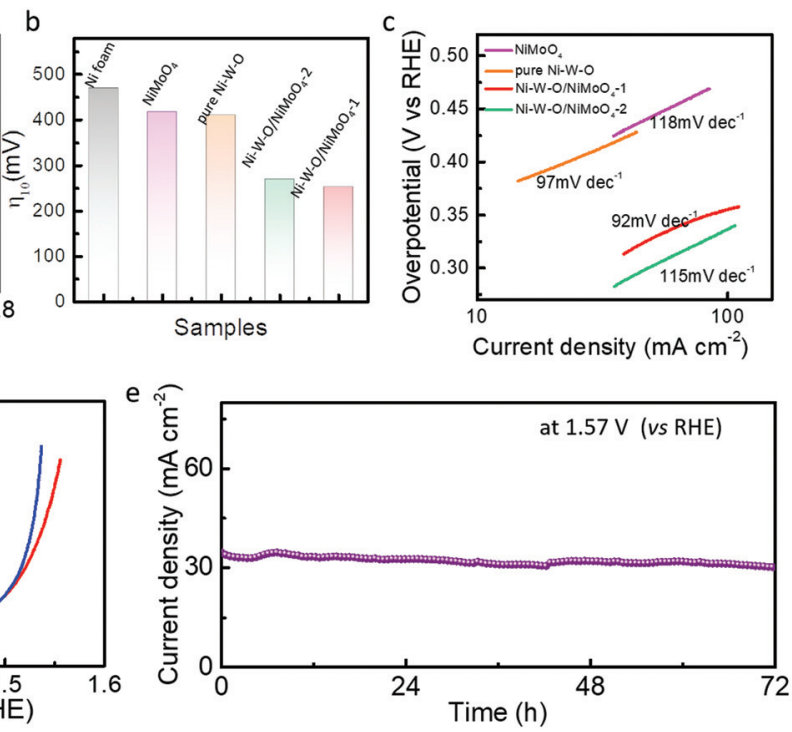

Fig. 4 Electrochemical activity in an $\mathrm{O}_{2}$-saturated $1.0 \mathrm{M} \mathrm{KOH}$ solution for OER. (a) OER polarization curves at a scan rate of $5 \mathrm{mV} \mathrm{s}^{-1}$. (b) Comparison of $\eta_{30}$ collected based on polarization curves in (a) for various electrodes. (c) Tafel plots for the $\mathrm{Ni}-\mathrm{W}-\mathrm{O} / \mathrm{NiMoO}-1$ heterostructure and other samples in alkaline media. (d) Comparison of the polarization curves before and after $5000 \mathrm{CV}$ cycles. (e) Chronoamperometry response at $1.57 \mathrm{~V}$ (vs. $\mathrm{RHE}$ ) for the $\mathrm{Ni}-\mathrm{W}-\mathrm{O} / \mathrm{NiMoO}_{4}-1$ electrode for 3 days.

ligible decay can be noticed from the chronoamperometric test (Fig. 3e) during the continuous generation of $\mathrm{H}_{2}$ gas. This further corroborated the durability of our material in prolonged activities.

In addition to the observed superb HER performance, we found that this $\mathrm{Ni}-\mathrm{W}-\mathrm{O} / \mathrm{NiMoO}_{4}$ heterostructure is also highly active toward electrocatalytic OER in the same electrolyte (1.0 M KOH) saturated with pure $\mathrm{O}_{2}$ gas $(99.99 \%)$. The polarization curves of various electrodes in Fig. 4a show a feature such that the oxidation peak appears at around $1.4 \mathrm{~V}$, which is ascribed to the oxidation of $\mathrm{Ni}^{2+}$ to $\mathrm{Ni}^{3+} \cdot{ }^{24,27}$ The overpotentials at the current density of $30 \mathrm{~mA} \mathrm{~cm}{ }^{-2}\left(\eta_{30}\right)$ were obtained to evaluate the OER performances of the $\mathrm{Ni}-\mathrm{W}-\mathrm{O} / \mathrm{NiMoO}_{4}-1$ and other electrodes (Fig. 4b). It was evident that pure $\mathrm{NiMoO}_{4}$ and $\mathrm{Ni}-$ $\mathrm{W}-\mathrm{O}$ are inferior electrocatalysts for OER with large overpotentials of 418 and $410 \mathrm{mV}$ at $30 \mathrm{~mA} \mathrm{~cm}{ }^{-2}$, respectively. Notably, the $\mathrm{Ni}-\mathrm{W}-\mathrm{O} / \mathrm{NiMoO}_{4}-1$ electrode showed remarkable OER activity with $\eta_{30}$ of only $253 \mathrm{mV}$, outperforming most of the previously reported electrocatalysts (Table $\mathrm{S} 2 \dagger$ ) such as commercial $\mathrm{IrO}_{2}\left(281 \mathrm{mV}\right.$ at $\left.10 \mathrm{~mA} \mathrm{~cm}{ }^{-2}\right)$, CoV-UAH $(250 \mathrm{mV}$ at $\left.10 \mathrm{~mA} \mathrm{~cm}{ }^{-2}\right),{ }^{28}\left(\mathrm{Co}_{4} \mathrm{Mn}_{1}\right) \mathrm{Se}_{2}\left(274 \mathrm{mV}\right.$ at $\left.10 \mathrm{~mA} \mathrm{~cm}{ }^{-2}\right),{ }^{29}$ and NG-NiFe $/ \mathrm{MoC}_{2}\left(320 \mathrm{mV}\right.$ at $\left.10 \mathrm{~mA} \mathrm{~cm}{ }^{-2}\right) .{ }^{30}$ It is noteworthy that the $\mathrm{Ni}-\mathrm{W}-\mathrm{O} / \mathrm{NiMoO}_{4}-2$ electrode demonstrated reasonable OER activity with $\eta_{30}$ of $270 \mathrm{mV}$. Meanwhile, the Tafel slope of $\mathrm{Ni}-\mathrm{W}-\mathrm{O} / \mathrm{NiMoO}_{4}-1$ was around $92 \mathrm{mV} \mathrm{dec}^{-1}$, substantiating its favourable electrode kinetics for OER. From the EIS spectra (Fig. S11 $\dagger$ ), we observed small $R_{\text {ct }}(1.7 \Omega)$ and $R_{\mathrm{s}}(0.9 \Omega)$ for the $\mathrm{Ni}-\mathrm{W}-\mathrm{O} / \mathrm{NiMoO}_{4}-1$ electrode at a potential of $0.64 \mathrm{~V}$. In contrast, the $\mathrm{NiMoO}_{4}$ electrode showed large $R_{\mathrm{ct}}$. This might be associated with the fact that the effective improvement in the electronic interaction between $\mathrm{Ni}-\mathrm{W}-\mathrm{O}$ and $\mathrm{NiMoO}_{4}$ endowed this heterostructure with an accelerated charge transfer process. The synergistic effect from the hierarchical heterostructure formation is therefore crucial for enhanced OER activity in alkaline media. Electrochemical durability is another key index to evaluate the performance of electrocatalysts. Significantly, after 5000 cycling tests (Fig. 4d), the polarization curve is almost identical to the original curve. The long-term electrochemical testing was also probed at a potential of $1.57 \mathrm{~V}$ (Fig. 4e), revealing a nearly constant current density after 3 days $(72 \mathrm{~h})$ of continuous operation. These results demonstrate the excellent stability of the $\mathrm{Ni}-\mathrm{W}-\mathrm{O} /$ $\mathrm{NiMoO}_{4}-1$ heterostructure in the alkaline electrolyte. After the long-term test, there was no obvious change in the crystal phase and components (Fig. S12-S14 $\dagger$ ), demonstrating the robust durability of $\mathrm{Ni}-\mathrm{W}-\mathrm{O} / \mathrm{NiMoO}_{4}-1$ during the continuous OER process.

Considering the remarkable HER and OER performances of the $\mathrm{Ni}-\mathrm{W}-\mathrm{O} / \mathrm{NiMoO}_{4}-1$ electrode in $1.0 \mathrm{M} \mathrm{KOH}$, we further used this heterostructure as a cathode and anode simultaneously for overall water splitting in the same solution. Impressively, the cell voltage to afford the current density of $30 \mathrm{~mA} \mathrm{~cm}{ }^{-2}$ was as low as $\sim 1.6 \mathrm{~V}$ (Fig. $5 \mathrm{a}$ ). The inset in Fig. $5 \mathrm{a}$ is the optical image of the system, where $\mathrm{O}_{2}$ and $\mathrm{H}_{2}$ are released constantly from the surface of the electrodes. Also, its overall water-splitting performance was superior to those of most of the previously reported non-noble metal bifunctional electrodes (Fig. 5b) including $\mathrm{Ni}_{1} \mathrm{Cr}_{1}-\mathrm{LDH},{ }^{31} \mathrm{Co}_{4} \mathrm{Ni}_{1} \mathrm{P}$ NTs, ${ }^{32}$ and $\mathrm{CoP}$ nanowires ${ }^{33,34-39}$ to deliver the same current density $\left(30 \mathrm{~mA} \mathrm{~cm}{ }^{-2}\right)$. We further tested the long-term durability of our $\mathrm{Ni}-\mathrm{W}-\mathrm{O} / \mathrm{NiMoO}_{4}-1$ electrode at $1.68 \mathrm{~V}$ for $30 \mathrm{~h}$ (Fig. $5 \mathrm{c}$ ). The fairly constant current density of $30 \mathrm{~mA} \mathrm{~cm}{ }^{-2}$ elucidated outstanding stability, which is necessary to realize scalability in practical applications. 

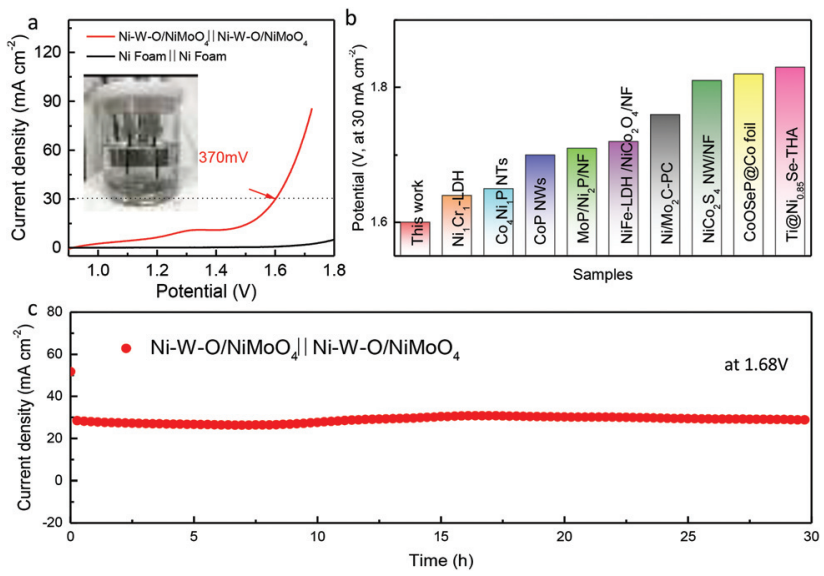

Fig. 5 The overall water splitting performance of the $\mathrm{Ni}-\mathrm{W}-\mathrm{O} /$ $\mathrm{NiMoO}_{4}-1$ heterostructure tested in $1.0 \mathrm{M} \mathrm{KOH}$ solution. (a) Polarization curve. (b) Comparison of the overall water splitting cell voltage at a current density of $30 \mathrm{~mA} \mathrm{~cm}{ }^{-2}$ for $\mathrm{Ni}-\mathrm{W}-\mathrm{O} / \mathrm{NiMoO}_{4}-1$ with other bifunctional electrocatalysts. These data were extracted from the published figures in accordance with ref. 31-39. (c) Chronoamperometry response of the $\mathrm{Ni}-\mathrm{W}-\mathrm{O} / \mathrm{NiMoO}_{4}-1$ electrode at $1.68 \mathrm{~V}$.

\section{Conclusions}

In conclusion, an $\mathrm{Ni}-\mathrm{W}-\mathrm{O} / \mathrm{NiMoO}_{4}$ heterostructure was successfully synthesized on a porous $\mathrm{Ni}$ foam. It could be used as a bifunctional HER and OER electrocatalyst in alkaline media. The presence of $\mathrm{Ni}-\mathrm{W}-\mathrm{O}$ nanosheets on pure $\mathrm{NiMoO}_{4}$ rods, which is crucial for constructing the hierarchical heterostructure, could significantly improve the electrocatalytic activity. A small overpotential $\left(\eta_{10}\right)$ of $52 \mathrm{mV}$ for hydrogen evolution was achieved. Meanwhile, the $\mathrm{Ni}-\mathrm{W}-\mathrm{O} / \mathrm{NiMoO}_{4}$ electrode demonstrated a superior OER performance with an overpotential of $253 \mathrm{mV}$ at a current density of $30 \mathrm{~mA} \mathrm{~cm}{ }^{-2}$ and superb stability after continuous testing for more than 3 days. The effective improvement in the electronic interaction between $\mathrm{Ni}-\mathrm{W}-\mathrm{O}$ and $\mathrm{NiMoO}_{4}$ endowed this heterostructure with outstanding electrochemical activity. Considering the remarkable HER and OER performances in alkaline media, overall water splitting using the $\mathrm{Ni}-\mathrm{W}-\mathrm{O} / \mathrm{NiMoO}_{4}$ heterostructure as an anode and cathode exhibited a cell voltage of $1.60 \mathrm{~V}$ at a current density of $30 \mathrm{~mA} \mathrm{~cm}{ }^{-2}$ with outstanding stability. This work paves the way for the future explorations of earth-abundant, binder-free and efficient electrocatalysts for practical overall water splitting.

\section{Experimental methods}

\section{Synthesis of $\mathrm{NiMoO}_{4}$ rods}

All chemicals were directly used without purification. First, a piece of $\mathrm{Ni}$ foam with a size of $2 \mathrm{~cm} \times 3 \mathrm{~cm}$ was dipped in 1.0 $\mathrm{M} \mathrm{HCl}$ for 15 min under ultrasonication, followed by washing several times with deionized water and ethanol. Then, $1.046 \mathrm{~g}$ of nickel nitrate hexahydrate $\left(\mathrm{Ni}\left(\mathrm{NO}_{3}\right)_{2} \cdot 6 \mathrm{H}_{2} \mathrm{O}, 98 \%\right.$, Alfa Aesar) and $0.176 \mathrm{~g}$ of ammonium molybdate (para)hydrate
$\left(\left(\mathrm{NH}_{4}\right)_{6} \mathrm{Mo}_{7} \mathrm{O}_{24} \cdot x \mathrm{H}_{2} \mathrm{O}, 99.999 \%\right.$, Alfa Aesar) were dissolved in $30 \mathrm{~mL}$ deionized water for $1 \mathrm{~h}$ with vigorous stirring to form a uniform solution. The clear solution was transferred to a $50 \mathrm{~mL}$ Teflon-lined stainless steel autoclave with a $\mathrm{Ni}$ foam and then, the reaction was maintained for $6 \mathrm{~h}$ at $150{ }^{\circ} \mathrm{C}$. Subsequently, the Teflon-lined stainless steel autoclave was cooled to room temperature and the sample was washed with deionized water and ethanol. Finally, it was dried at $60^{\circ} \mathrm{C}$ and annealed at $500{ }^{\circ} \mathrm{C}$ in $\mathrm{H}_{2} / \mathrm{Ar}(5: 95)$ for $2 \mathrm{~h}$ for further measurement.

\section{Synthesis of $\mathrm{Ni}-\mathrm{W}-\mathrm{O} / \mathrm{NiMoO}_{4}$ heterostructure}

Typically, $1.0 \mathrm{mmol}$ of nickel chloride hexahydrate $\left(\mathrm{NiCl}_{2} \cdot 6 \mathrm{H}_{2} \mathrm{O}\right.$, Aladdin) and $1.0 \mathrm{mmol}$ of ammonium tungsten oxide hydrate $\left(\left(\mathrm{NH}_{4}\right)_{10} \mathrm{~W}_{12} \mathrm{O}_{41} \cdot x \mathrm{H}_{2} \mathrm{O}\right.$, Alfa Aesar) were dissolved in $30 \mathrm{~mL}$ deionized water. The homogeneous solution was transferred to a $50 \mathrm{~mL}$ Teflon-lined stainless steel autoclave and reacted at $130{ }^{\circ} \mathrm{C}$ for $8 \mathrm{~h}$. After the reaction, the obtained $\mathrm{Ni}-\mathrm{W}-\mathrm{O} / \mathrm{NiMoO}_{4}-1$ heterostructure was taken out, washed with deionized water and ethanol and then dried at $60{ }^{\circ} \mathrm{C}$ for $2 \mathrm{~h}$. Similarly, the $\mathrm{Ni}-\mathrm{W}-\mathrm{O} / \mathrm{NiMoO}_{4}-2$ heterostructure was synthesized using $2 \mathrm{mmol}$ of $\mathrm{NiCl}_{2} \cdot 6 \mathrm{H}_{2} \mathrm{O}$ and $2 \mathrm{mmol}$ of $\left(\mathrm{NH}_{4}\right)_{10} \mathrm{~W}_{12} \mathrm{O}_{41} \cdot x \mathrm{H}_{2} \mathrm{O}$.

\section{Structural characterization}

The morphologies of $\mathrm{NiMoO}_{4}$ rods, Ni-W-O microcubes and $\mathrm{Ni}-\mathrm{W}-\mathrm{O} / \mathrm{NiMoO}_{4}$ heterostructure were characterized via scanning electron microscopy (SEM, Hitachi S-4800 SEM) at $20 \mathrm{kV}$ and transmission electron microscopy (TEM, JEOL JEM-2100F) at $200 \mathrm{kV}$ including the components of the materials. The crystal phase was confirmed by X-ray diffraction (XRD, Bruker D8 Focus) using $\mathrm{Cu} \mathrm{K}_{\alpha}$ irradiation $(\lambda=1.5406 \AA$ A). X-ray photoelectron spectroscopy was performed using an ESCALab250 electron spectrometer from Thermo Fisher Scientific Corporation with monochromatic $150 \mathrm{~W}$ Al $\mathrm{K}_{\alpha}$ radiation. The pass energy for the narrow scan was $30 \mathrm{eV}$. The base pressure was about $6.5 \times 10^{-10}$ mbar. The binding energies were referenced to the $\mathrm{C} 1 \mathrm{~s}$ line at $284.8 \mathrm{eV}$ from alkyl or adventitious carbon.

\section{Electrochemical measurements}

The electrochemical activities of the $\mathrm{NiMoO}_{4}$ rods, $\mathrm{Ni}-\mathrm{W}-\mathrm{O}$ microcubes and $\mathrm{Ni}-\mathrm{W}-\mathrm{O} / \mathrm{NiMoO}_{4}$ heterostructure were studied in an electrochemical station (Princeton Applied Research PARSTAT MC) using a typical three-electrode system. The different electrocatalysts grown on the Ni foam acted as the working electrodes with glassy carbon and $\mathrm{Hg} / \mathrm{HgO}$ electrode as the counter and reference electrodes, respectively. All the overpotentials were standardized to RHE via the equation $E_{\mathrm{RHE}}=E_{\mathrm{Hg} / \mathrm{HgO}}+0.098+0.059 \times \mathrm{pH}$. The electrocatalytic hydrogen evolution measurements were carried out in $1.0 \mathrm{M} \mathrm{KOH}$ saturated with $\mathrm{N}_{2}$ for HER, and linear sweep voltammetry (LSV) curves were collected from $-0.85 \mathrm{~V}$ to $-1.5 \mathrm{~V}$ at a scan rate of $5 \mathrm{mV} \mathrm{s}^{-1}$. Electrochemical impedance spectroscopy (EIS) in the frequency range from $100 \mathrm{~Hz}$ to $0.1 \mathrm{~Hz}$ was conducted at $-1 \mathrm{~V}$. The stability of the $\mathrm{Ni}-\mathrm{W}-\mathrm{O} / \mathrm{NiMoO}_{4}$ hetero- 
structure was exhibited via CV with 5000 continuous cycles from $-0.9 \mathrm{~V}$ to $-1.25 \mathrm{~V}$ and chronoamperometry under the potential of $0.11 \mathrm{~V}$ (vs. $\mathrm{Hg} / \mathrm{HgO}$ electrode) for HER. For the OER measurements, LSV was tested from $0.25 \mathrm{~V}$ to $0.9 \mathrm{~V}(v s$. $\mathrm{RHE}$ ) under an $\mathrm{O}_{2}$-saturated electrolyte. EIS was conducted at $0.64 \mathrm{~V}$ ( vs. $\mathrm{Hg} / \mathrm{HgO}$ electrode) using the same frequency range. For the stability test, the potential range for CV was from $0.3 \mathrm{~V}$ to $0.65 \mathrm{~V}$, and chronoamperometry was carried out at $1.57 \mathrm{~V}$. The exchange current densities of various electrocatalysts were obtained by fitting the linear portion of the Tafel plot at a low cathodic current density, such that the value was calculated according to the Tafel equation. The point at which the abscissa (i.e., current density axis) intersects the extension of the Tafel plot is the value of the exchange current density. During overall water splitting, the Ni-W-O/NiMoO${ }_{4}^{-1}$ heterostructure acting as the cathode and the anode simultaneously was investigated in a two-electrode system with the selected potential range from $0.8 \mathrm{~V}$ to $1.8 \mathrm{~V}$. Continuous testing at the constant potential of $1.68 \mathrm{~V}$ was utilized to evaluate its stability. All the polarization curves were corrected for IR compensation throughout the system to present intrinsic activity.

\section{Conflicts of interest}

There are no conflicts to declare.

\section{Acknowledgements}

This work was supported by National Natural Science Foundation of China (No. 61625401, 61474033, 61574050, 11674072, 21805057, 21703047), Ministry of Science and Technology of China (No. 2016YFA0200700), Strategic Priority Research Program of the Chinese Academy of Sciences (Grant No. XDA09040201), and CAS Key Laboratory of Nanosystem and Hierarchical Fabrication.

\section{References}

1 M. Grätzel, Nature, 2001, 414, 338.

2 F. Wang, T. A. Shifa, X. Zhan, Y. Huang, K. Liu, Z. Cheng, C. Jiang and J. He, Nanoscale, 2015, 7, 19764-19788.

3 N. Cheng, S. Stambula, D. Wang, M. N. Banis, J. Liu, A. Riese, B. Xiao, R. Li, T.-K. Sham, L.-M. Liu, G. A. Botton and X. Sun, Nat. Commun., 2016, 7, 13638.

4 J. Mahmood, F. Li, S.-M. Jung, M. S. Okyay, I. Ahmad, S.-J. Kim, N. Park, H. Y. Jeong and J.-B. Baek, Nat. Nanotechnol., 2017, 12, 441.

5 J. Kibsgaard and T. F. Jaramillo, Angew. Chem., Int. Ed., 2014, 53, 14433-14437.

6 X. Long, G. Li, Z. Wang, H. Zhu, T. Zhang, S. Xiao, W. Guo and S. Yang, J. Am. Chem. Soc., 2015, 137, 11900-11903.

7 D. Y. Chung, S. W. Jun, G. Yoon, H. Kim, J. M. Yoo, K.-S. Lee, T. Kim, H. Shin, A. K. Sinha, S. G. Kwon, K. Kang,
T. Hyeon and Y.-E. Sung, J. Am. Chem. Soc., 2017, 139, 6669-6674.

8 S. Huang, Y. Meng, S. He, A. Goswami, Q. Wu, J. Li, S. Tong, T. Asefa and M. Wu, Adv. Funct. Mater., 2017, 27, 1606585.

9 K. Liu, F. Wang, P. He, T. A. Shifa, Z. Wang, Z. Cheng, X. Zhan and J. He, Adv. Energy Mater., 2018, 8, 1703290.

10 Y. Yang, Z. Lin, S. Gao, J. Su, Z. Lun, G. Xia, J. Chen, R. Zhang and Q. Chen, ACS Catal., 2017, 7, 469-479.

11 L. Yu, H. Zhou, J. Sun, F. Qin, F. Yu, J. Bao, Y. Yu, S. Chen and Z. Ren, Energy Environ. Sci., 2017, 10, 1820-1827.

12 Z. Zhang, X. Ma and J. Tang, J. Mater. Chem. A, 2018, 6, 12361-12369.

13 K. Hu, M. Wu, S. Hinokuma, T. Ohto, M. Wakisaka, J.-i. Fujita and Y. Ito, J. Mater. Chem. A, 2019, 7, 2156-2164.

14 Y. Wang, Y. Sun, F. Yan, C. Zhu, P. Gao, X. Zhang and Y. Chen, J. Mater. Chem. A, 2018, 6, 8479-8487.

15 H. Xu, J. Wei, K. Zhang, Y. Shiraishi and Y. Du, ACS Appl. Mater. Interfaces, 2018, 10, 29647-29655.

16 Y. Yang, H. Fei, G. Ruan, C. Xiang and J. M. Tour, ACS Nano, 2014, 8, 9518-9523.

17 S.-H. Bae, J.-E. Kim, H. Randriamahazaka, S.-Y. Moon, J.-Y. Park and I.-K. Oh, Adv. Energy Mater., 2017, 7, 1601492.

18 S. Yin, W. Tu, Y. Sheng, Y. Du, M. Kraft, A. Borgna and R. Xu, Adv. Mater., 2018, 30, 1705106.

19 R. Subbaraman, D. Tripkovic, K.-C. Chang, D. Strmcnik, A. P. Paulikas, P. Hirunsit, M. Chan, J. Greeley, V. Stamenkovic and N. M. Markovic, Nat. Mater., 2012, 11, 550 .

20 Z. Li, X. Dou, Y. Zhao and C. Wu, Inorg. Chem. Front., 2016, 3, 1021-1027.

21 B. Hinnemann, P. G. Moses, J. Bonde, K. P. Jørgensen, J. H. Nielsen, S. Horch, I. Chorkendorff and J. K. Nørskov, J. Am. Chem. Soc., 2005, 127, 5308-5309.

22 J. Zhang, T. Wang, P. Liu, Z. Liao, S. Liu, X. Zhuang, M. Chen, E. Zschech and X. Feng, Nat. Commun., 2017, 8, 15437.

23 M. S. Faber, R. Dziedzic, M. A. Lukowski, N. S. Kaiser, Q. Ding and S. Jin, J. Am. Chem. Soc., 2014, 136, 10053-10061.

24 K. Xiao, L. Xia, G. Liu, S. Wang, L.-X. Ding and H. Wang, J. Mater. Chem. A, 2015, 3, 6128-6135.

25 L. Niu, Z. Li, Y. Xu, J. Sun, W. Hong, X. Liu, J. Wang and S. Yang, ACS Appl. Mater. Interfaces, 2013, 5, 8044-8052.

26 W. He, Z. Liang, K. Ji, Q. Sun, T. Zhai and X. Xu, Nano Res., 2018, 11, 1415-1425.

27 Z. Y. Yu, C. C. Lang, M. R. Gao, Y. Chen, Q. Q. Fu, Y. Duan and S. H. Yu, Energy Environ. Sci., 2018, 11, 1890-1897.

28 J. Z. Liu, Y. F. Ji, J. W. Nai, X. G. Niu, Y. Luo, L. Guo and S. H. Yang, Energy Environ. Sci., 2018, 11, 1736-1741.

29 X. Zhao, X. Li, Y. Yan, Y. Xing, S. Lu, L. Zhao, S. Zhou, Z. Peng and J. Zeng, Appl. Catal., B, 2018, 236, 569-575.

30 Q. Hu, X. Liu, B. Zhu, L. Fan, X. Chai, Q. Zhang, J. Liu, C. He and Z. Lin, Nano Energy, 2018, 50, 212-219.

31 W. Ye, X. Fang, X. Chen and D. Yan, Nanoscale, 2018, 10, 19484-19491. 
32 L. Yan, L. Cao, P. Dai, X. Gu, D. Liu, L. Li, Y. Wang and X. Zhao, Adv. Funct. Mater., 2017, 27, 1703455.

33 W. Li, X. Gao, D. Xiong, F. Xia, J. Liu, W. G. Song, J. Xu, S. M. Thalluri, M. F. Cerqueira, X. Fu and L. Liu, Chem. Sci., 2017, 8, 2952-2958.

34 C. Du, M. Shang, J. Mao and W. Song, J. Mater. Chem. A, 2017, 5, 15940-15949.

35 Z. Wang, S. Zeng, W. Liu, X. Wang, Q. Li, Z. Zhao and F. Geng, ACS Appl. Mater. Interfaces, 2017, 9, 1488-1495.
36 Z. Y. Yu, Y. Duan, M. R. Gao, C. C. Lang, Y. R. Zheng and S. H. Yu, Chem. Sci., 2017, 8, 968-973.

37 A. Sivanantham, P. Ganesan and S. Shanmugam, Adv. Funct. Mater., 2016, 26, 4661-4672.

38 Y.-F. Jiang, C.-Z. Yuan, X. Zhou, Y.-N. Liu, Z.-W. Zhao, S.-J. Zhao and A.-W. Xu, Electrochim. Acta, 2018, 292, 247255.

39 C. Yang, J. Zhang, G. Gao, D. Liu, R. Liu, R. Fan, S. Gan, Y. Wang and Y. Wang, ChemSusChem, 2019, 12, 1-8. 